\title{
Efeitos da corrosão acelerada na aderência de vergalhões em concretos com fibras de aço
}

\author{
Effects of accelerated corrosion on rebar \\ bonding in steel fiber concrete
}

Antonio Renato Albuquerque Bicelli ${ }^{1}$, Vinicius Amaral de Oliveira ${ }^{1}$, Karina dos Santos Pizzolato Matos ${ }^{1}$, Dênio Ramam Carvalho de Oliveira ${ }^{1}$

\footnotetext{
${ }^{1}$ Faculdade de Engenharia Civil, Universidade Federal do Pará, UFPA, Rua Augusto Corrêa, 1, CEP 66075-110, Belém, PA, Brasil.

e-mail: renato.bicelli@gmail.com, eng.viniciusamaral@gmail.com, karina.pizzolato@gmail.com, denio@ufpa.br
}

\begin{abstract}
RESUMO
A utilização de fibras de aço no concreto vem recebendo forte atenção pela possibilidade de reduzir significativamente o consumo de barras de aço nas estruturas de concreto armado. Entretanto, ainda são poucos os trabalhos encontrados sobre a durabilidade de concreto com fibra de aço e sobre o desempenho da ancoragem das barras metálicas em concretos reforçados e submetidos a ataques de íons cloreto. Buscando contribuir para o melhor entendimento do assunto, este trabalho apresenta resultados para 12 (doze) amostras prismáticas (100x100x250) $\mathrm{mm}^{3}$. Cada amostra recebeu uma barra de aço de $8 \mathrm{~mm}$ de diâmetro que foram divididas em 2 (dois) grupos iguais, sendo que um grupo foi submetido ao ensaio de corrosão acelerada por imersão modificada (CAIM) e o outro não, avaliando-se os danos ocasionados pelo ataque de íons cloreto tanto nas barras quanto nas fibras de aço. Cada grupo apresentou 3 (três) amostras com 1\% de fibra de aço e outros 3 (três) sem fibra, e os comprimentos de ancoragem $\left(l_{b}\right)$ foram de $100 \%, 75 \%$ e $50 \%$ necessário daquele recomendado pela norma Brasileira NBR 6118. Verificou-se que não há comprometimento da perda de aderência das barras com o substrato de concreto, quando reduzido o $\left(l_{b}\right)$ em $25 \%$ garantindo a funcionalidade, podendo resultar em redução de custos. Observou-se ainda que nas amostras submetidas a corrosão com fibras ou sem fibras houve perda de massa, não sendo constatado que a presença de fibras possa ter contribuído para reduzir essa perda, contudo é possível observar uma relação direta entre o menor valor de $\left(l_{b}\right)$ e a menor perda de massa.
\end{abstract}

Palavras-chave: Comprimento de ancoragem; Fibra de Aço; Aderência; Corrosão.

\section{ABSTRACT}

The implementation of steel fibers in concrete has received strong attention, for the possibility of significantly reducing steel bar's consumption in reinforced concrete structures. However, a small number of articles is found on the durability of steel fiber concrete and the performance of anchorage length, when submitted to chloride ion attacks. Seeking to contribute to the better understanding of the subject, this paper presents results for 12 (twelve) prismatic samples $(100 \times 100 \times 250) \mathrm{mm}^{3}$. Each sample received a steel bar within $8 \mathrm{~mm}$ in diameter, and these were divided into 2 (two) equal groups, which only the first group was subjected to the modified immersion accelerated corrosion test, in order to evaluate the damage caused by the attack of chloride ions on both bars and steel fibers. Each group presented 3 (three) samples with $1 \%$ of steel fiber and another 3 (three) without fiber, and the anchorage lengths $\left(l_{b}\right)$ vary between $100 \%, 75 \%$ and $50 \%$, as recommended by Brazilian standard NBR 6118. It was verified that there was no compromise related to the adhesion's loss between steel bar and concrete substrate, when reduced the $\left(l_{b}\right)$ by $25 \%$ and guarantees functionality, which can result in cost reduction. In addition, the corrosion resulted in a loss of $50 \%$ of the value of the maximum pullout load.

Keywords: Anchorage length; Steel fiber; Adhesion; Corrosion. 


\section{INTRODUÇÃO}

A construção exige soluções inovadoras para otimizar tanto o processo construtivo quanto os materiais utilizados devido à alta competitividade do mercado. A introdução de fibras de aço no concreto pode ser uma solução que contribua com a durabilidade do concreto, quando submetido ao ambiente infestado por cloreto, melhorando as suas características. Vários autores no mundo discutem os benefícios da fibra de aço nas estruturas de concreto e WANG et al. [1] afirma que a fibra de aço vem gerando resultados a longo prazo, no qual vem chamando a atenção de pesquisadores do ramo da construção. A escolha do material, fibra de aço, para compor a estrutura do concreto, visa manter ou até mesmo melhorar a capacidade de resistência desta estrutura, considerando uma possível diminuição no comprimento de ancoragem e armadura suscetível ao processo de oxidação. $\mathrm{O}$ desenvolvimento do trabalho para avaliar os efeitos da corrosão acelerada e aderência de barras de aço em concretos com fibras de aço, resulta na análise de como um material inserido, no composto padrão de concreto armado pode contribuir na durabilidade da estrutura.

De acordo com SHIMOSAKA ([2], apud FIGUEIREDO, [3]), o concreto apresenta o posto de material estrutural mais utilizado no mundo devido a várias características, no entanto existe algumas limitações como a baixa deformação à tração quando solicitado, comportamento frágil, e por isso o incremento da fibra de aço ajuda a diminuir estes efeitos. Além disso, o uso da fibra de aço pode reduzir a perda de massa por corrosão. Estruturas de concreto expostas à ambientes agressivos e reativos tornam-se vulneráveis a uma deterioração mais acelerada, a corrosão afeta diretamente a durabilidade, pois diminui a seção do aço, reduzindo a vida útil da estrutura. Dessa maneira, se faz necessário um alto investimento em manutenção para garantir capacidade de a estrutura resistir às influências ambientais previstas e definidas na elaboração do projeto, ou seja, na durabilidade da estrutura, conforme a NBR 6118 [4].

$\mathrm{Na}$ literatura internacional, muitos trabalhos sobre corrosão de estruturas em concreto armado podem ser encontrados, ressaltando os trabalhos recentes sobre análises experimentais realizadas por PENG et. al. [5] e simulações numéricas feitas por XIA et. al. [6] e SOLA et. al. [7]. PENG et al. [5] apresentaram dados experimentais sobre o processo de corrosão em concreto armado através de ondas ultrassónicas que são capazes de medir a porcentagem de corrosão no aço através das amplitudes e frequência das ondas analisadas. Xia et. al. [6] apresentam simulações numéricas da corrosão do aço em concretos contaminados com cloreto, analisando dois parâmetros que medem a concentração de ions de cloreto presente na amostra e assim medindo a corrosão. Por último, SOLA et. al. [7] realizaram estudos numéricos e experimentais de corrosão acelerada em concreto armado, analisando a deterioração da estrutura, através da perda de massa e monitorando o padrão das fissuras geradas.

Neste contexto, e para simular a corrosão real de estruturas em concreto armado, dentro de um intervalo de tempo menor para ser possível o seu estudo em laboratório, foi desenvolvido por Lima [8] o ensaio de corrosão acelerada por imersão modificada (CAIM) a partir de um estudo similar realizado por VARELA e ESPINOSA [9].

Outra variável é o comprimento de ancoragem, fundamental para a estrutura pois está relacionado com a aderência da barra de aço no concreto, tendo como objetivo garantir que não ocorra seu escorregamento. De maneira geral, as estruturas de concreto armado não conseguem apresentar bom desempenho quando suas armaduras estão corroídas, sendo essencial para garantir sua durabilidade, o controle da qualidade do concreto, dimensionamento adequado, espessura de cobrimento e manutenção da estrutura. AMLEH [10] afirma que em ambientes agressivos com alto teor de salinidade, como pontes ou edifícios próximos do mar, faz-se necessário a utilização de outras medidas preventivas contra a corrosão. Neste contexto, o ensaio de Corrosão Acelerada por Imersão Modificada (CAIM) tem como função simular o comportamento da corrosão do aço, avaliando-se a perda de massa da barra que foi submetida ao ensaio. Nesse sentido, este artigo compara os resultados de amostras de referência com amostras corroídas, variando-se o teor de fibra de aço no concreto e o comprimento de ancoragem $\left(l_{b}\right)$, sendo que o comprimento de referência foi definido de acordo com a NBR 6118 [4].

A aderência entre o concreto e a barra de aço é que garante que a deformação da armadura, de modo geral, seja semelhante à das camadas de concreto adjacentes. Ao se restringir a visão para um comportamento localizado, tem-se uma avaliação mais complexa, pois deve-se levar em consideração as descontinuidades, tais como as fissuras e os deslocamentos relativos entre armadura e concreto, pois as deformações destes elementos não são iguais, comprovado pelo coeficiente de dilatação próprio de cada um destes materiais, segundo FERNANDES [11]. Pode-se definir aderência como sendo o mecanismo de transferência de tensões que existe na interface entre a barra de aço da armadura e o concreto que a envolve. Na ancoragem por aderência, deve ser previsto um comprimento suficiente para que o esforço da barra (de tração ou de compressão) seja transferido para o concreto, sendo denominado comprimento de ancoragem. THOMPSON et al. [12] afirma que quando a tensão de ligação é suficiente para resistir ao carregamento na barra, o comprimento necessário para a satisfatória 
ancoragem da barra inteiramente solicitada é denominado como comprimento de desenvolvimento.

A quantificação dessa ligação aço - concreto pode ser avaliada pela relação da tensão de aderência com o deslizamento, representada pela variação da tensão que surge na interface do aço com o concreto relacionada ao deslocamento relativo entre barra da armadura e o concreto envolvente, sendo que os valores máximos desse deslizamento podem ser usados para definir a destruição da aderência (FERNANDES [11]. Conforme ACI 408.2R-12 [13] a tensão de aderência $\left(\tau_{b}\right)$ refere-se às tensões que, ao longo da interface da ligação barraconcreto, modificam as tensões do aço ao longo do comprimento total da barra, por meio da transferência de carregamento entre a barra e o concreto envolvente. Podem aparecer de duas formas, sendo a primeira resultante da ancoragem ou no comprimento de aderência de ancoragem e a segunda referente a variação da força ao longo da barra.

\section{MATERIAIS E MÉTODOS}

Foram moldadas amostras prismáticas de concreto sem ou com fibras de aço, sendo que cada amostra apresentou uma barra nervurada de aço (vergalhão) parcialmente embutida no concreto, para serem submetidas a ensaios de corrosão acelerada por imersão modificada (CAIM) e, posteriormente, a ensaios de arrancamento visando avaliar os efeitos da corrosão nas barras de aço e da variação de seus comprimentos de ancoragem em suas resistências ao arrancamento.

\subsection{Memória de cálculo}

Foi utilizada a norma brasileira NBR 6118 [4] como referência para estimar o comprimento de ancoragem $\left(l_{b}\right)$. O aço considerado foi do tipo CA-50 como barras de diâmetro $(\varnothing)$ igual a $8,0 \mathrm{~mm}$. O valor da tensão de escoamento do aço $\left(f_{\mathrm{ys}}\right)$ corresponde a $500 \mathrm{MPa}$, valor máximo permitido pela norma. Para o concreto foi adotado como valor correspondente à classe $\mathrm{C} 30$, ou seja, $f_{c}$ igual a $30 \mathrm{MPa}$, comumente utilizado na construção brasileira. Com esses valores e usando a Equação 1 foi possível determinar a resistência à tração direta característica $\left(f_{c t k}\right)$ de 2,02 MPa.

$$
f_{c t k}=0,7 \cdot 0,3 \cdot f_{c}^{2 / 3}
$$

De posse do valor de $f_{c t k}$ foi então realizado o cálculo da tensão de aderência entre a armadura e o concreto na ancoragem $\left(f_{b k}\right)$, considerando as recomendações da NBR 6118 [4], os coeficientes adotados foram $\eta_{1=} 2,25$ (barras nervuradas), $\eta_{2=1} 1,0$ (boa aderência) e $\eta_{3=} 1,0(\varnothing<32,0 \mathrm{~mm}$ ). A Equação 2 viabiliza o cálculo de $f_{b k}$, que corresponde a 4,56 MPa. O valor de $l_{b}$ é determinado pela Equação 3, que resulta em $219 \mathrm{~mm}$. Segundo a NBR 6118 [4], o $l_{b}$ deve respeitar a condição definida pela Equação 4. Como $l_{b}$ é maior do que o permitido, o valor adotado para o comprimento de ancoragem será 25 vezes o diâmetro da barra, correspondente a $200 \mathrm{~mm}$. Foram realizados ensaios de tração axial nas barras de aço seguindo as recomendações da NBR 6892 [14], e os resultados mostraram que a tensão de escoamento $\left(f_{y s}\right)$ foi de $585 \mathrm{MPa}$ com uma deformação $\left(\varepsilon_{y s}\right)$ de $3,0 \%$.

$$
\begin{aligned}
& f_{b k}=\eta 1 \bullet \eta 2 \cdot \eta 3 \cdot 0,21 \\
& l_{b}=\frac{\emptyset \bullet f_{y s}}{f_{b k} \cdot 4} \\
& l_{b}=\frac{\emptyset \bullet f_{y s}}{f_{b k} \cdot 4}<25 \bullet \emptyset
\end{aligned}
$$

\subsection{Características das amostras}

Foram confeccionadas 12 amostras prismáticas de dimensões (100x100x250) $\mathrm{mm}^{3}$, sendo 6 delas para o ensaio de corrosão seguido do ensaio de aderência, e o restante somente para o ensaio de arrancamento. As dimensões foram definidas com base nas recomendações da NBR 6118 [4], tendo em vista se adequarem ao cobrimento normativo de $40 \mathrm{~mm}$ para elementos estruturais de concreto armado em ambiente marítimo. Foi posicionado uma barra nervurada (vergalhão) de aço CA-50 com diâmetro de $8,0 \mathrm{~mm}$, tendo seu comprimento de ancoragem variando entre $100 \%, 75 \%$ e $50 \%$ e conectadas a um fio de cobre para a realização do ensaio de corrosão (figuras 2 e 3), posicionadas com o auxílio de fios de nylon para garantir o $l_{b}$. Além disso, cada barra apresentou um comprimento de $150 \mathrm{~mm}$ externo ao concreto para atender aos requisitos operacionais do ensaio de arrancamento. 
Utilizou-se dois tipos de concreto neste experimento, ambos contendo o mesmo traço em massa (1: 2,3: 3,2: 0,55), sendo composto por areia, seixo e cimento Portland CP II-E. Foi utilizado $1 \%$ em massa de aditivo superplastificante para auxiliar durante a confecção do concreto e garantir o abatimento de $100 \mathrm{~mm} \pm 20 \mathrm{~mm}$, facilitando sua trabalhabilidade. Em um dos tipos de concreto que foram confeccionados havia a presença de $1 \%$ de fibra de aço. A fibra de aço utilizada é classificada de acordo com a NBR 15530 [15] como Tipo C (fibra de aço corrugada) e Classe II (fibra oriunda de chapa laminada cortada a frio), como pode ser visto na Figura 1. Foi realizado ensaios de compressão axial em 12 corpos de prova cilíndricos de $(100 \times 200) \mathrm{mm}^{2}$ com o objetivo de avaliar a sua resistência de compressão simples, sendo 6 deles com a fibra de aço (CP1F ao CP6F) e o restante sem a fibra (CP1 ao CP6). A Tabela 1 apresenta as principais características de cada amostra. As figuras 2, 3 e 4 mostram as principais etapas da confecção das amostras.

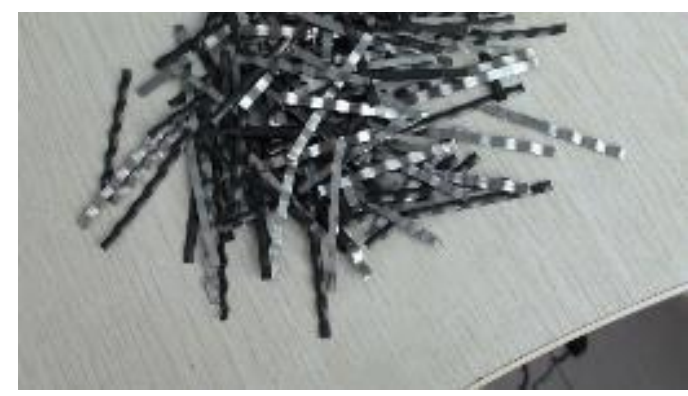

Figura 1: Fibra de aço tipo C e classe II.

Tabela 1: Características das amostras.

\begin{tabular}{cccc}
\hline Amostra & $\boldsymbol{l}_{\boldsymbol{b}}(\%)$ & $\mathbf{1 \%}$ Fibra & CAIM \\
\hline P1 & & Não & Não \\
P2 & \multirow{2}{*}{100} & Não & Sim \\
P3 & & Sim & Não \\
P4 & & Sim & Sim \\
\hline P5 & & Não & Não \\
P6 & \multirow{2}{*}{75} & Não & Sim \\
P7 & & Sim & Não \\
P8 & & Sim & Sim \\
\hline P9 & & Não & Não \\
P10 & & Não & Sim \\
P11 & 50 & Sim & Não \\
P12 & & Sim & Sim \\
\hline
\end{tabular}
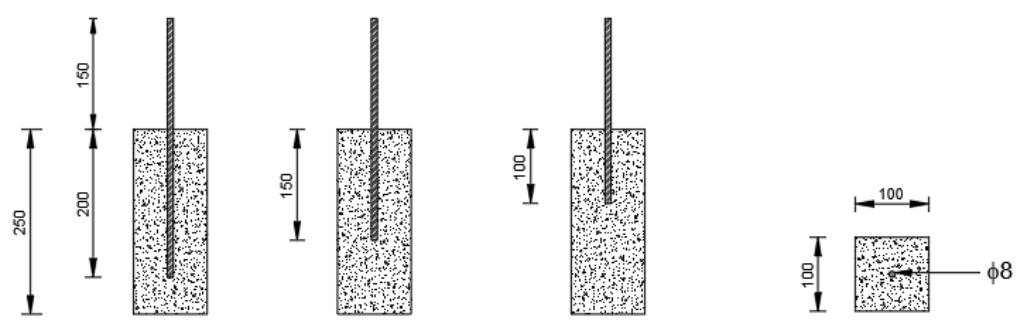

Vista frontal das amostras

Figura 2: Dimensões das amostras. 


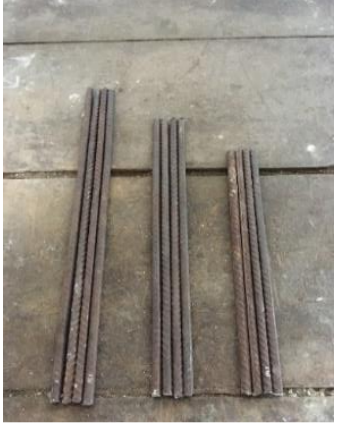

(a)

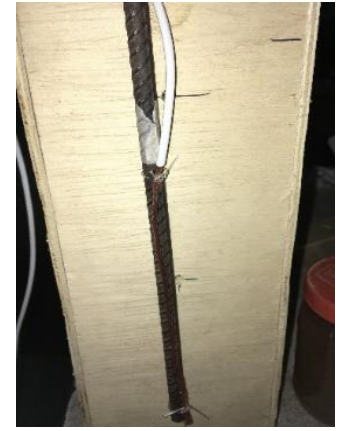

(b)

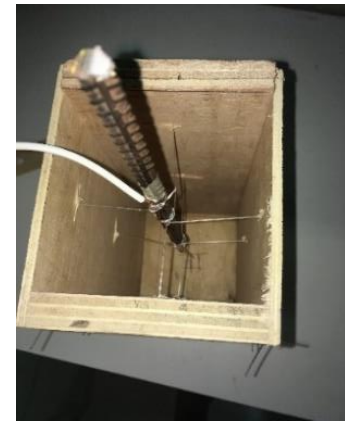

(c)

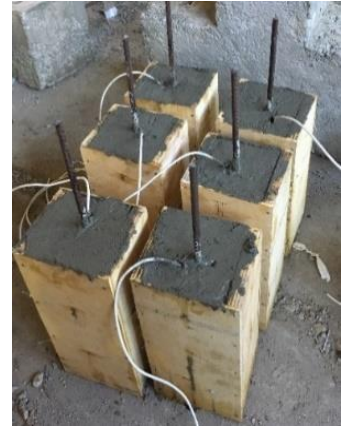

(d)

Figura 3: Preparo das armaduras. (a) Corte das barras, (b) Posicionamento da fiação na barra, (c) Posicionamento da barra na forma, (d) Amostras após a concretagem.

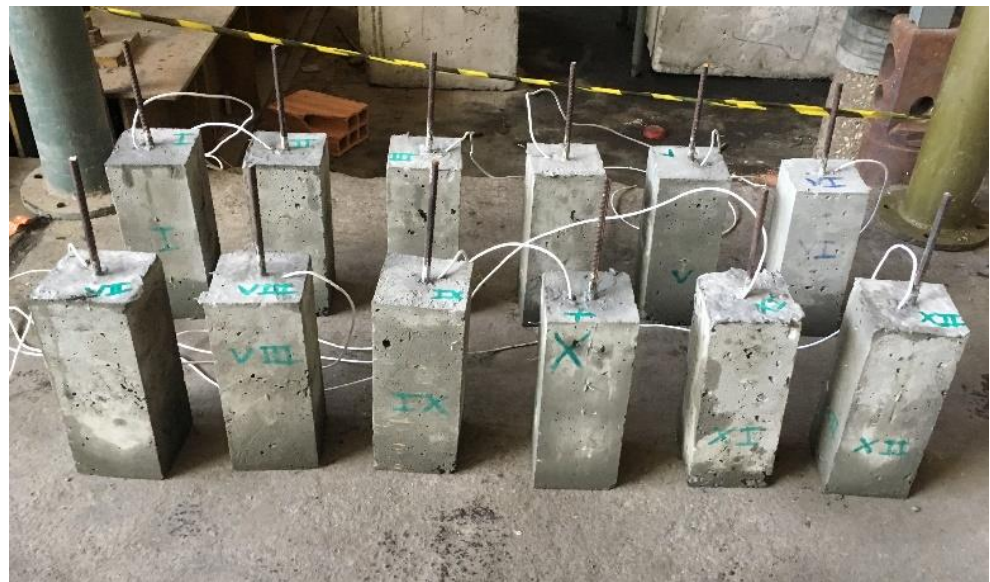

Figura 4: Amostras extraídas das formas.

\subsection{Ensaio de corrosão}

O ensaio de corrosão adotado foi o ensaio de corrosão acelerada por imersão modificada (CAIM). Os parâmetros escolhidos para este ensaio têm como base o experimento realizado por TORRES [16]. A Figura 5 mostra como o ensaio CAIM foi configurado. Utilizou-se como recipiente o poliestireno expansivo de 50 litros, tendo a capacidade de suportar 3 amostras simultaneamente (Figura 6). A voltagem de indução utilizada foi de 48 Volts, com corrente elétrica máxima de 5 amperes e potência de 250 Watts. Fios de cobre são posicionados na armadura do corpo de prova e ligados no polo positivo de uma fonte de tensão constante, enquanto que o polo negativo da fonte elétrica foi conectado a uma barra de cobre, submersa em uma solução salina, com uma concentração aproximada a da água do mar, de 35 gramas (g) de $\mathrm{NaCl}$ por litro de água, resultando em uma corrente de fluxo contínua. A parte da barra de aço externa ao concreto foi isolada da solução, para assegurar que o fluxo de íons chegasse na barra somente através da penetração pelo concreto (Figura 7).

Dessa maneira, 6 amostras foram submetidas a 24 horas de ensaio, com o nível de solução adotado até metade da seção transversal, ou seja, aproximadamente $50 \mathrm{~mm}$, para assegurar ambas a absorção da corrente e a aeração necessária, para o efeito de corrosão em todas as seções transversais da barra. O nível de água era ajustado devido à evaporação, visando manter constante o nível de água na metade da seção transversal da amostra. A barra de aço é pesada antes e depois do experimento, com o intuito de avaliar a diferença de peso ocasionada pela corrosão, segundo TORRES [16]. Dentre os principais fatores para dimensionar sistemas de ancoragem, os dois principais são a aderência dos materiais (concreto e aço) e o comprimento do embutimento ou ancoragem. FERNANDES [11] define a aderência como sendo o fator que relaciona as transferências de tensões, existentes na barra de aço e no concreto que a envolve. A NBR 6118 [4] fornece a equação para dimensionar o comprimento de ancoragem necessário, podendo variar de acordo com a característica do concreto e a natureza do aço. 


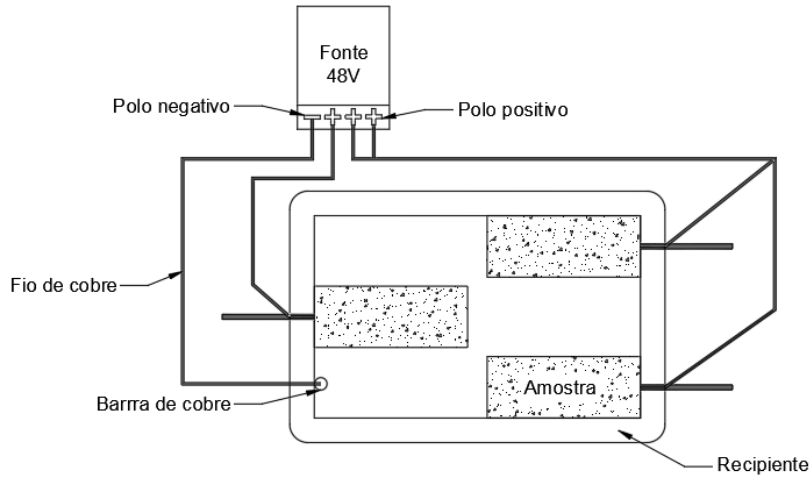

(a)

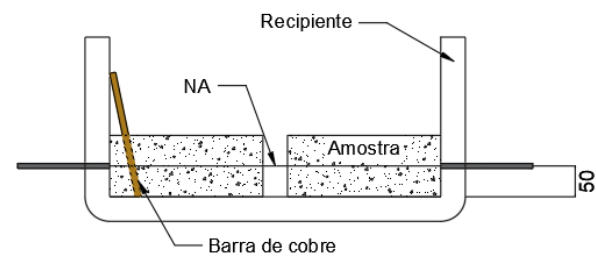

(b)

Figura 5: Detalhamento do ensaio CAIM. (a) Vista superior do ensaio CAIM. (b) Vista Frontal do ensaio CAIM

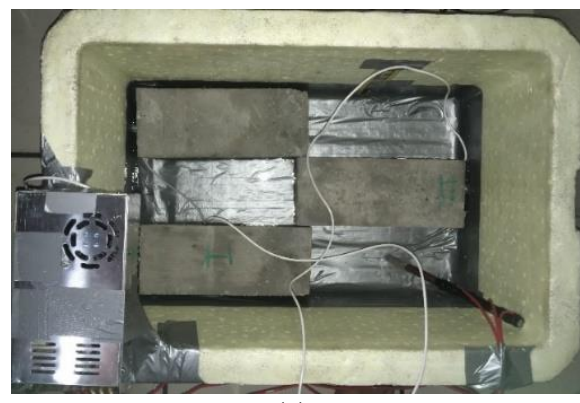

(a)

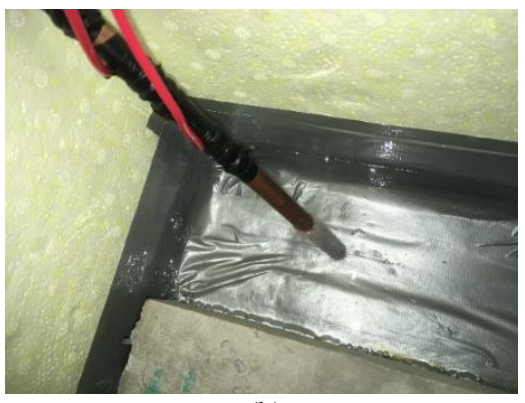

(b)

Figura 6: Execução do ensaio CAIM. (a) Arranjo das amostras no recipiente. (b) Detalhe da barra e fio condutor

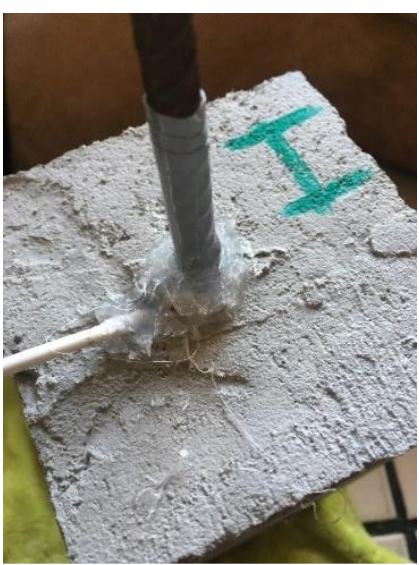

(a)

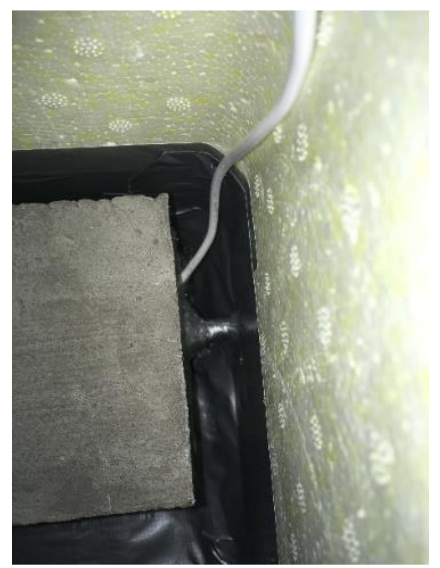

(b)

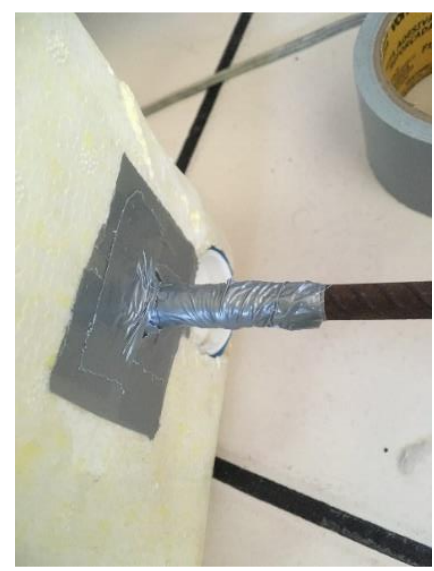

(c)

Figura 7: Detalhe do isolamento da parte da barra externa ao concreto. (a) Isolamento da conexão. (b) Vista superior do isolamento. (c) Isolamento do recipiente, conexão externa.

\subsection{Ensaio de aderência}

O ensaio de aderência foi realizado através de uma máquina de tração simples. Por necessidade operacional, foi definido $150 \mathrm{~mm}$ da barra externa ao concreto, e também, foi utilizado uma gaiola metálica para limitar o deslocamento do concreto, deslocando desta forma somente o aço. A tração foi aplicada até o rompimento da barra de aço, ou até o deslizamento da mesma. As figuras 8 (a) até (c) mostram os detalhes do ensaio. 


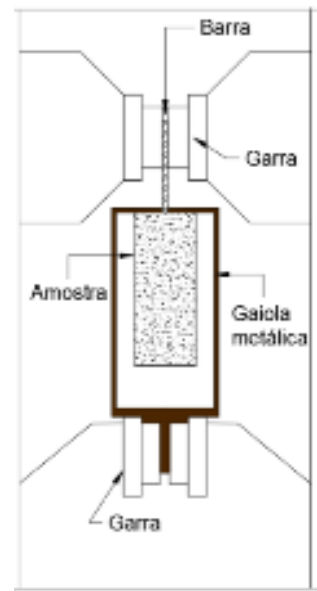

(a)

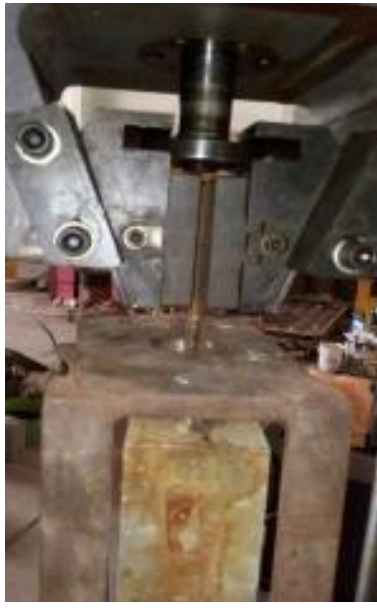

(b)

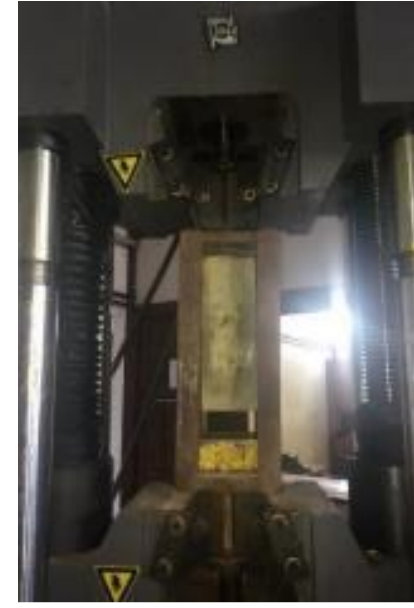

(c)

Figura 8: Ensaio de tração simples. (a) Visão esquemática da máquina de tração. (b) Detalhe da amostra na máquina. (c)

Realização do ensaio.

\subsection{Limpeza e caracterização das barras}

Antes e após o ensaio CAIM, as barras de aço foram pesadas para medir a diferença de massa perdido através da corrosão. Após o ensaio do CAIM, as barras foram propriamente removidas dos corpos de provas e imersa em uma solução de limpeza recomendada pela American Society for Testing and Materials (ASTM A380 [17]) também citado em TORRES [16]. A solução de limpeza foi gerada pela dissolução de $580 \mathrm{~g}$ de ácido clorídrico e de 3,5 g de hexametilenotetramina em água, até que se complete um litro de solução. As barras ficaram imersas na solução de limpeza por 45 minutos, sendo lavadas em água corrente (Figura 9). As barras foram devidamente secadas e pesadas posteriormente.

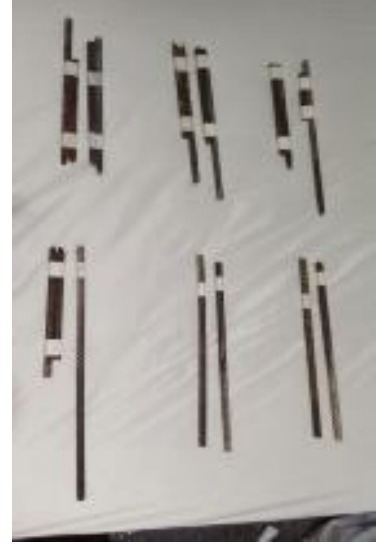

(a)

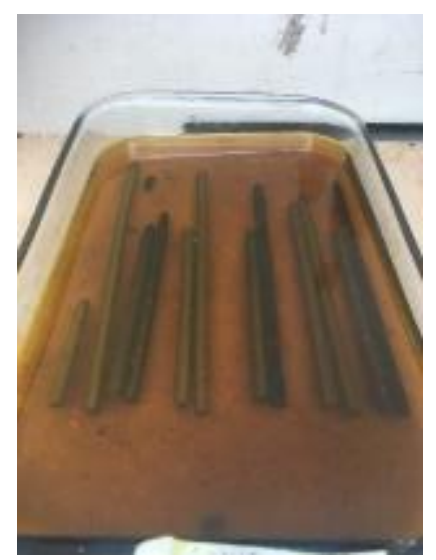

(b)

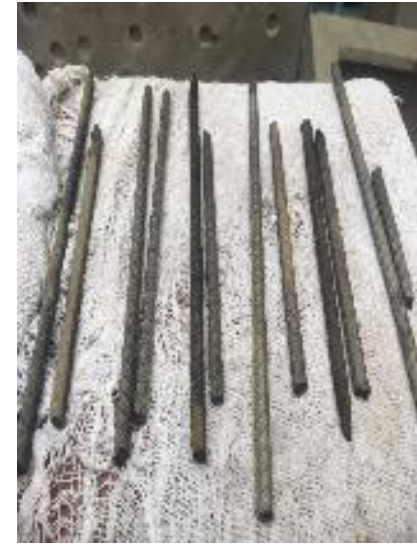

(c)

Figura 9: Procedimento de limpeza das barras. (a) Procedimento de limpeza e barras etiquetadas. (b) Barras na solução química de limpeza. (c) Barras após a limpeza química.

\section{RESULTADOS E DISCUSSÃO}

\subsection{Ensaio de compressão axial}

O ensaio foi realizado em uma máquina universal (tração e compressão) com o auxílio de um prato de aço e borracha Neoprene nas extremidades dos corpos de prova, como pode ser visto na Figura 10. A Tabela 2 apresenta os resultados dos ensaios, sendo que $f_{c j}$ foi obtido pela média dos resultados aos 28 dias de idade. Os valores para a resistência característica à compressão do concreto foram de 32,7 MPa para as amostras sem fibra e 33,8 MPa para as amostras com fibra. 
Tabela 2: Resultado do ensaio de compressão axial.

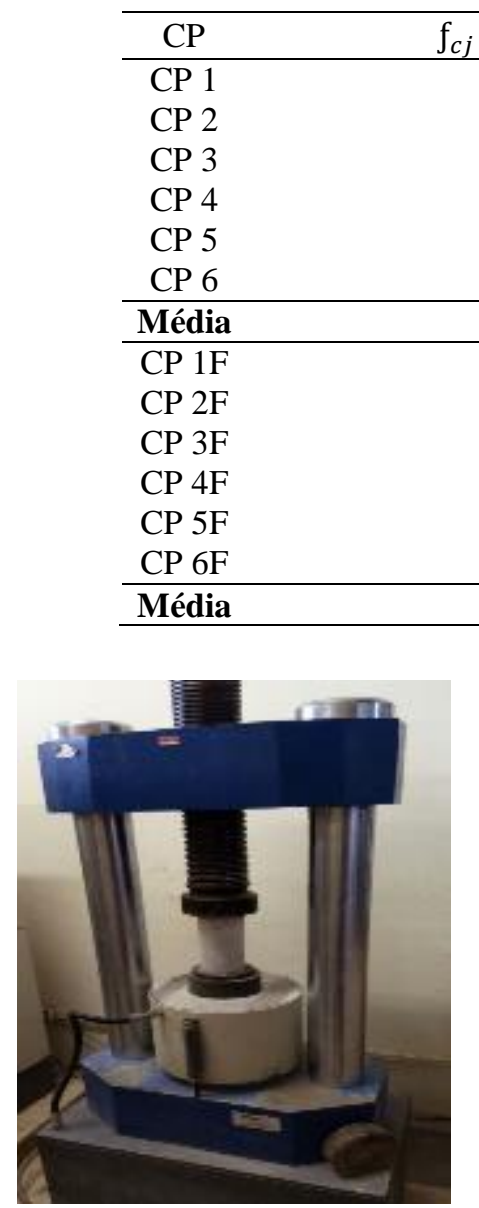

(a)

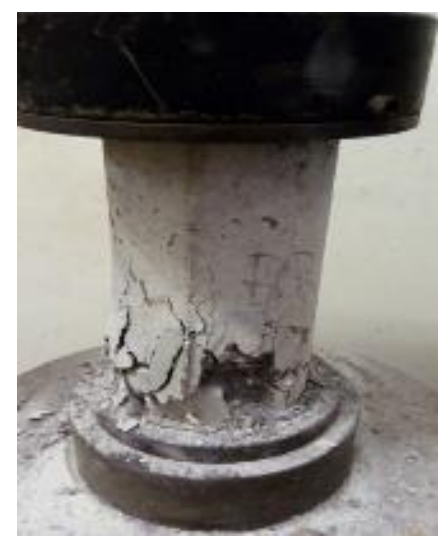

(b)

Figura 10: Ensaio de compressão axial. (a) Amostra posicionado na prensa. (b) Amostra após rompimento.

\subsection{Resultados do ensaio CAIM}

A Tabela 3 mostra os resultados do ensaio de corrosão da barra de aço, seu peso inicial $\left(P_{i}\right)$, peso final $\left(P_{f}\right)$, a variação de massa $\left(\Delta_{m}\right)$ e o percentual dessa variação. As amostras que não participaram do ensaio CAIM não obtiveram alteração em seu peso. As figuras 11, 12 e 13 mostram comparações entre amostras corroídas e as não corroídas. É possível observar que os efeitos da corrosão no concreto são claros, mesmo com o ensaio sendo realizado por apenas 24 horas. As figuras 13(a) e (b) mostram a parte interna das amostras não corroídas e corroídas, respectivamente, onde as fibras de aço são visíveis e apresentaram efeitos discretos da corrosão devido à proteção alcalina do concreto, resumindo-se a machas suaves, talvez provenientes da corrosão nas barras de aço.

Tabela 3: Perda de massa das barras de aço.

\begin{tabular}{ccccccc}
\hline Fibras (1\%) & Amostra & $\boldsymbol{l}_{\boldsymbol{b}}(\boldsymbol{\%})$ & $\boldsymbol{P}_{\boldsymbol{i}}(\mathbf{g})$ & $\boldsymbol{P}_{\boldsymbol{f}}(\mathbf{g})$ & $\boldsymbol{\Delta}_{\boldsymbol{m}}(\mathbf{g})$ & $\boldsymbol{\Delta}_{\boldsymbol{m}}(\boldsymbol{\%})$ \\
\hline \multirow{4}{*}{ Sim } & P4 & 100 & 137,7 & 129,2 & 8,6 & 6,2 \\
& P8 & 75 & 116,9 & 111,2 & 5,7 & 4,9 \\
& P12 & 50 & 97,5 & 93,2 & 4,3 & 4,4 \\
\hline \multirow{3}{*}{ Não } & P2 & 100 & 138,5 & 132,2 & 6,3 & 4,6 \\
& P6 & 75 & 117,6 & 112,1 & 5,5 & 4,6 \\
& P10 & 50 & 98,3 & 92,8 & 5,5 & 5,6 \\
\hline
\end{tabular}




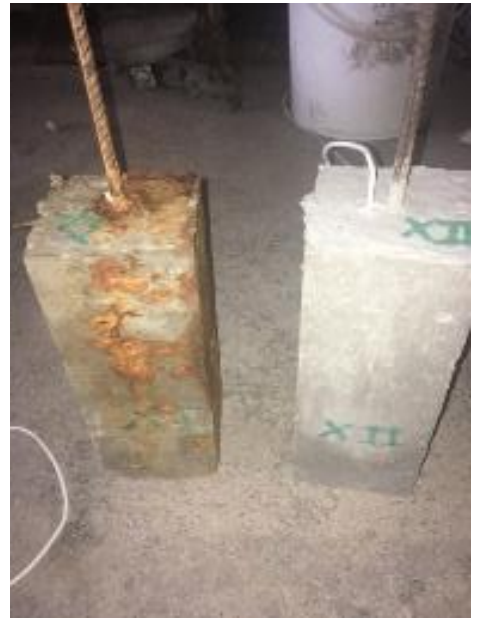

Figura 11: Comparação visual entre amostras que foram submetidas ao ensaio de CAIM e não.

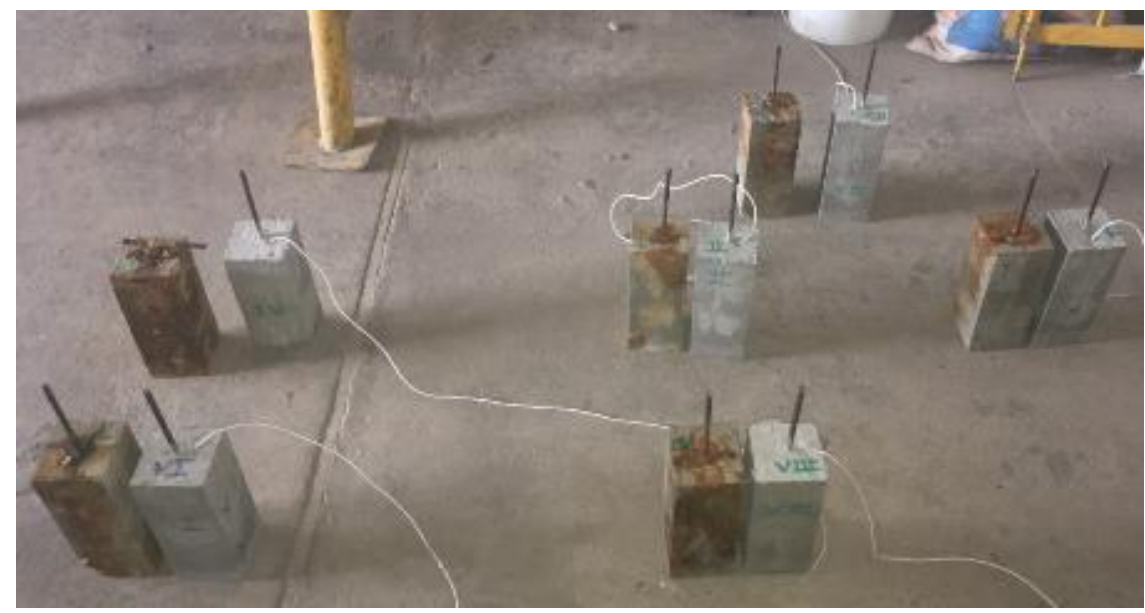

Figura 12: Aspecto final das amostras.

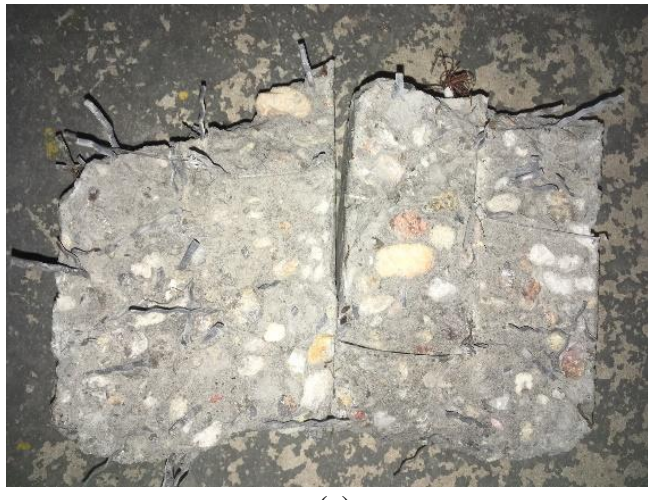

(a)

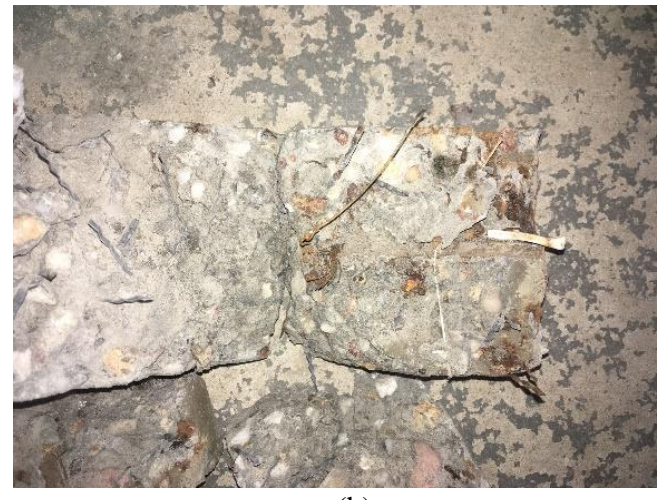

(b)

Figura 13: Amostras rompidas. (a). Não submetida ao CAIM. (b) Submetida ao CAIM.

\subsection{Resultados do ensaio de arrancamento}

A Tabela 4 apresenta os resultados dos ensaios de arrancamento nas amostras. Nas amostras P1 a P4, que apresentaram $100 \%$ do $l_{b}, \mathrm{P} 2$ e P4 apresentaram perda de massa de 4,6 \% e 6,2 \%, em relação à P1 e P3, respectivamente. P1 e P3 não foram submetidos a ensaios de corrosão. Pode-se verificar que as amostras que sofreram corrosão perderam aproximadamente $50 \%$ do valor médio de sua carga máxima de arrancamento $\left(F_{\max , T}\right)$ quando comparadas às amostras que não perderam massa. Analisando o efeito da adição de fibra de aço, pode-se concluir que o teor de $1 \%$ não ocasionou alteração significativa no valor de $F_{\max , T}$. Todas as amostras com $100 \%$ do comprimento de ancoragem apresentaram seccionamento das barras ao final dos ensaios. 
Considerando as amostras de P5 a P8, que apresentaram $75 \%$ de $l_{b}$, observa-se que P6 e P8 apresentaram perdas de massa de 4,6 \% e 4,9 \%, quando comparadas às amostras P5 e P7, respectivamente, e ambas atingiram $50 \%$ da carga de ruptura média de seu grupo. P5 e P7 não foram submetidos a ensaios de corrosão e as amostras P5 a P7 apresentaram seccionamento das barras ao final dos ensaios, sendo que em P8 a barra deslizou. Já para as amostras P9 a P12, que apresentaram $50 \%$ do $l_{b}$, observou-se que P10 e P12 perderam 5,6\% e 4,4 \% de z de massa, quando comparadas às amostras P9 e P11, respectivamente. Pode-se verificar que as amostras que sofreram corrosão apresentaram resistência média ao arrancamento de $54 \%$ do valor médio apresentado pelas amostras que não sofreram corrosão em seu grupo. Todas as amostras com $50 \%$ do comprimento de ancoragem normativo apresentaram deslizamento das barras.

Tabela 4: Dados das amostras.

\begin{tabular}{cccccc}
\hline Amostra & $\boldsymbol{F}_{\boldsymbol{m a x}, \boldsymbol{T}}(\mathbf{k N})$ & $\boldsymbol{l}_{\boldsymbol{b}}(\boldsymbol{\%})$ & $\mathbf{1 \%}$ Fibra & CAIM & $\boldsymbol{\Delta}_{\boldsymbol{m}}(\boldsymbol{\%})$ \\
\hline P1 & 38,1 & & Não & Não & - \\
P2 & 18,5 & \multirow{2}{*}{100} & Não & Sim & 4,60 \\
P3 & 38,3 & & Sim & Não & - \\
P4 & 19,8 & & Sim & Sim & 6,20 \\
\hline P5 & 37,4 & & Não & Não & - \\
P6 & 18,2 & \multirow{2}{*}{75} & Não & Sim & 4,60 \\
P7 & 39,0 & & Sim & Não & - \\
P8 & 19,8 & & Sim & Sim & 4,90 \\
\hline P9 & 28,7 & & Não & Não & - \\
P10 & 15,7 & 50 & Não & Sim & 5,60 \\
P11 & 29,7 & & Sim & Não & - \\
P12 & 15,9 & & Sim & Sim & 4,40 \\
\hline
\end{tabular}

\section{CONCLUSÕES}

Conclui-se que o comprimento de ancoragem $\left(l_{b}\right)$ para barras de aço não corroídas apresentou resultados satisfatórios para $100 \%$ e $75 \%$ do valor normativo, mas para $50 \%$ desse valor pode ocorrer $20 \%$ de perda de resistência/arrancamento ou aderência, aproximadamente. A adição de $1 \%$ de fibra de aço não influenciou significativamente esta resistência e tão pouco a perda de massa das barras de aço embutidas nos concretos. Os efeitos da corrosão nas fibras de aço foram discretos. O ensaio CAIM apresentou desempenho satisfatórios ao ser realizado com fonte de $48 \mathrm{~V}$, duração de 24 horas e com volume de água até metade da seção da barra de aço, os resultados foram de 4,4 \% até 6,2 \% de perda de massa na barra de aço. Em média, para $5 \%$ de perda de massa na barra de aço, perde-se também $50 \%$ de resistência ao arrancamento ou aderência da barra de aço no concreto, ressaltando a relevância deste trabalho quando se dimensionam estruturas de concreto, com ou sem adição de fibras de aço, para ambientes sujeitos ao ataque de íons cloreto.

\section{BIBLIOGRAFICA}

[1] WANG, C, Experimental investigation on behavior of steel fiber reinforced concrete (SFRC). Tese de M.Sc., Department of Civil Engineering, University of Canterbury, 2006.

[2] SHIMOSAKA, T.J., Influência do teor de diferentes tipos de fibras de aço em concreto auto adensáveis. Tese de M.Sc., Universidade tecnologia federal do Paraná, 2017.

[3] FIGUEIREDO, A.D., Concreto Reforçado com Fibras. Concreto: Ciência e Tecnologia. IBRACON, volume 2, 2011.

[4] ASSOCIAÇÃO BRASILEIRA DE NORMAS TÉCNICAS. NBR 6118 - 2014 - Projeto e Execução de Obras de Concreto Armado - Procedimento. Rio de Janeiro, 2014.

[5] PENG, D., DONGYU, X., SHIFENG, H., et al., "Assessment of corrosion of reinforcing steel bars in concrete using embedded piezoelectric transducers based on ultrasonic wave", Construction and Building Materials, v. 151, pp 925-930, 2017.

[6] XIA, J., LI, T., FANG, J., et al., "Numerical simulation of steel corrosion in chloride contaminated concrete", Construction and Building Materials, v. 228, 2019.

[7] SOLA, E., OZBOLT, J., BALABANIC, G., et al., "Experimental and numerical study of accelerated corrosion of steel reinforcement in concrete: Transport of corrosion products", Gement and Concrete Research, v. 120, 2019.

[8] LIMA, M.G. Influência dos componentes do concreto na corrosão de armaduras, Tese de M.Sc., Universidade federal do Rio Grande do Sul, 1990. 
[9] VARELA, H., ESPINOZA, L.V., "Penetrabilidad de lones cloruors em morteiros com y sin revestimento", VII Jornadas chilenas del hormigon e I Jornada lationameticana del cimento y hormigones, Chile, 1988.

[10] AMLEH, L. "Influence of corrosion of reinforcing bars on the bond between steel and concrete". Tese D.Sc., McGill University, Canada, 1996.

[11] FERNANDES, R.M. "A influência das ações repetidas na aderência aço-concreto", Tese de M.Sc., Escola de Engenharia de São Carlos, Universidade de São Paulo, São Carlos, 2000.

[12] THOMPSON, M.K., JIRSA, J.O., BREEN, J.E., et al., "Anchorage Behavior of Headed Reiforcement", In: Research Report $N^{o}$ 1855-1, Center for Highway Research, The University of Texas at Austin, Texas, 2002.

[13] AMERICAN CONCRETE INSTITUTE COMMITTEE 408.2R-12: Report on Bond of Steel Reinforcing Bars Under Cyclic Loads.

[14] ASSOCIAÇÃO BRASILEIRA DE NORMAS TÉCNICAS. NBR 6892 - Materiais Metálicos - Ensaio de tração à temperatura ambiente. Rio de Janeiro, 2002.

[15] ASSOCIAÇÃO BRASILEIRA DE NORMAS TÉCNICAS. NBR 15530 - Fibras de aço para concreto Especificação. Rio de Janeiro, 2007.

[16] TORRES, A.S., “Avaliação da sensibilidade do ensaio CAIM - corrosão acelerada por imersão modificada - frente ao processo de corrosão em armaduras de concreto armado". Tese de M.Sc., Universidade Federal do Rio Grande do Sul, 2006.

[17] AMERICAN SOCIETY FOR TESTING AND MATERIALS. Annual book of ASTM Standards. Standard practice for cleaning, descaling and passivation of stainless steel parts, equipment and systems. ASTM A380, Philadelphia, 1996.

\section{ORCID}

Antonio Renato Albuquerque Bicelli

Vinicius Amaral de Oliveira

Karina dos Santos Pizzolato Matos

Dênio Ramam Carvalho de Oliveira https://orcid.org/0000-0002-0683-3252

https://orcid.org/0000-0003-3625-5884

https://orcid.org/0000-0003-4659-9955

https://orcid.org/0000-0001-8254-4551 